Archive for

Organic Chemistry

Arkivoc 2020, part v, 119-128

\title{
A concise, rapid and high yielding flow synthesis of aryldiazonium tetrafluoroborates
}

\author{
Chantal Scholtz and Darren L. Riley
}

Department of Chemistry, University of Pretoria, Lynnwood Road, Pretoria, South Africa

Email: darren.riley@up.ac.za

Received 09-15-2020

Accepted 11-04-2020

Published on line 11-17-2020

\section{Abstract}

A concise, rapid and high-yielding flow synthesis of aryl diazonium tetrafluoroborate salts is reported. The flow approach has been achieved by means of a diazotization reaction to access unstable aryl diazonium chloride salts in situ, followed by reaction with sodium tetrafluoroborate, to afford the corresponding aryldiazonium tetrafluoroborates in isolated yields of $64-100 \%$.

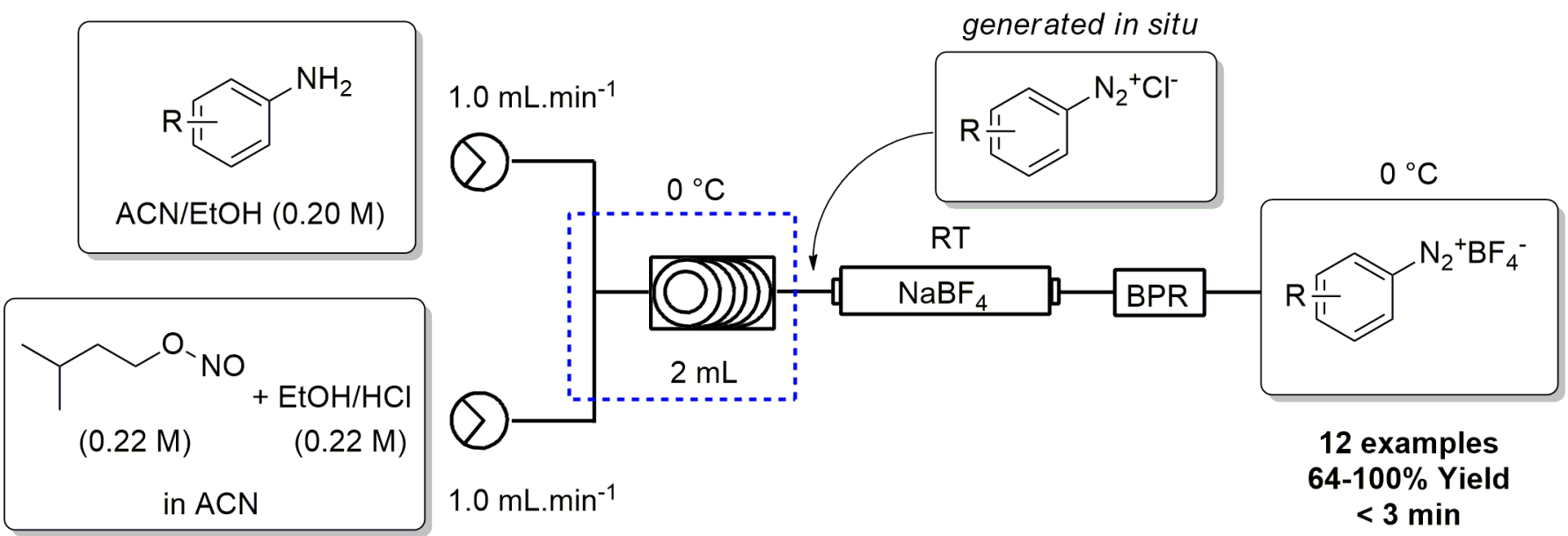

Keywords: Flow chemistry, aryldiazonium tetrafluoroborates, aryl diazonium salts 


\section{Introduction}

The synthesis of aryl diazonium salts was first reported by Griess in $1858 .{ }^{1,2}$ Since then, they have become important synthons in organic synthesis due, in part, to the ease with which the diazonium group can be displaced by a wide range of nucleophiles. ${ }^{3}$ In the last 160 years, the range of reactions involving diazonium salts has expanded from the development of the Sandmeyer reaction to obtain $\mathrm{C}-\mathrm{Cl}, \mathrm{C}-\mathrm{Br}$ and $\mathrm{C}-\mathrm{CN}$ bonds in 1884, and Pschorr intramolecular substitution reaction for the synthesis of biaryltricyclics in 1896 . $^{2}$ These were followed by the intermolecular Gomberg-Bachmann reaction in 1924 and, shortly thereafter in 1927, the BalzSchiemann reaction involving the thermal decomposition of diazonium tetrafluoroborates to obtain the difficult to access aryl C-F bond. ${ }^{2}$ The Meerwein arylation followed in 1939 and, 38 years later in 1977, Kikukawa and Matsuda laid the foundation for palladium-catalyzed cross-couplings. ${ }^{2}$ Since then, developments in C-C, C-B, C-S and C-N bond formation, with and without retention of $\mathrm{N}_{2}$, have been reported. ${ }^{4}$

In 2002, de Mello and co-workers reported, for the first time, the generation of a diazonium salt under flow conditions in which they used a nanoscale monolithic chip to prepare an aryl diazonium chloride, followed by in-situ quenching to obtain azo dyes. ${ }^{5}$ The same group subsequently demonstrated a linked in-situ chloro-dediazonation. ${ }^{6}$

The in-situ generation and use of aryl diazonium salts have subsequently been reported in several flow syntheses, ${ }^{7-11}$ as have the syntheses of related triazine moieties. ${ }^{12-15}$ In many instances, the syntheses suffered from solubility issues, requiring the use of large excesses of acid and nitrite or requiring complex and specialized reactor setups. A detailed overview of these approaches can be found in the 2015 review by Felpin and co-workers. ${ }^{16}$

The most widely utilised approach to access aryldiazonium tetrafluoroborate salts involves the diazotization of an aryl amine in the presence of sodium nitrite and hydrochloric acid under aqueous conditions. ${ }^{4,20-21}$ Thereafter, treatment with sodium tetrafluoroborate or fluoroboric acid results in the precipitation of the desired aryldiazonium tetrafluoroborate salt (Scheme 1).

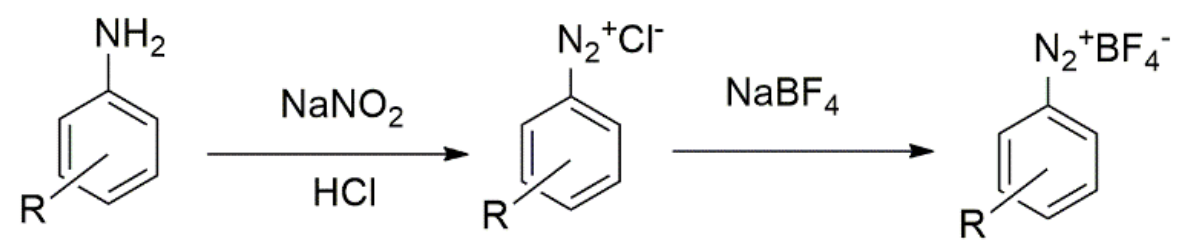

Scheme 1. General approach for the synthesis of aryl diazonium tetrafluorborate salts.

To date, the synthesis and/or use of aryldiazonium tetrafluoroborates under flow conditions has been limited. $\mathrm{Yu}$ and co-workers demonstrated a Balz-Schiemann reaction using aqueous sodium nitrite with a combination of hydrochloric and fluoroboric acids under aqueous conditions in a tubular reactor to form aryl diazonium tetrafluoroborate salts, followed by fluoro-dediazonation to obtain aryl fluorides in good yields. ${ }^{17} \mathrm{Li}$ and co-workers employed a similar approach during their flow synthesis of $N$-aryl pyrazoles generating diazonium tetrafluoroborate salts by reaction of anilines/BF $3 /$ THF with tert-butyl nitrite/THF in a tubular reactor. In this instance, the tube reactor was placed in a sonicator to prevent the build-up of precipitated diazonium salts. ${ }^{7}$ Baxendale and co-workers explored the generation of aryl diazonium chloride species under aqueous, organic, and solid-phase conditions, followed by the in-situ consumption of the diazonium species in downstream reactions. ${ }^{18}$ In one example, the diazotization of tert-butyl 4-aminophenylcarbamate was 
demonstrated by reaction with trimethylsilyl chloride/bromide and isopentyl nitrite, followed by off-line conversion to the more stable tetrafluoroborate salt. ${ }^{18}$

As part of an in-house research program we desired a convenient high-yielding approach for the preparation of aryldiazonium tetrafluoroborates for use as coupling partners in Suzuki-Miyaura reactions. Reported herein is a facile, high-yielding flow approach to access such systems.

\section{Results and Discussion}

In developing an approach that could be applied to a flow system, an initial batch-mode investigation/optimisation series of experiments were undertaken using aniline as a model system to identify conditions that would afford homogeneous reaction mixtures. Initially, sodium nitrite was exchanged for isopentyl nitrite, allowing the reactions to be performed in more solubilising organic solvents; several potential solvent systems were screened (Table 1$).^{4}$

Table 1. Batch optimisation for the preparation of aryl tetrafluoroborates

\begin{tabular}{|c|c|c|c|c|}
\hline \multirow{3}{*}{ Entry } & \multirow{3}{*}{ Solvent } & \multirow{2}{*}{\multicolumn{2}{|c|}{$\frac{\begin{array}{c}\text { 1. isopentyl nitrite, } \\
\text { solvent, acid }\end{array}}{\underset{\text { 2. } \mathrm{NaBF}_{4}}{\text { Acid }}}$}} & \multirow{3}{*}{ Yield (\%) } \\
\hline & & & & \\
\hline & & Source & Equiv. & \\
\hline 1 & None $^{a}$ & $32 \% \mathrm{HCl}$ & 5.1 & 3 \\
\hline 2 & DMF & $32 \% \mathrm{HCl}$ & 5.1 & 19 \\
\hline 3 & $\mathrm{H}_{2} \mathrm{O}$ & $32 \% \mathrm{HCl}$ & 5.1 & 20 \\
\hline 4 & 1:1 EtOH/DMF & $32 \% \mathrm{HCl}$ & 5.1 & 20 \\
\hline 5 & 1:1 EtOH/ $\mathrm{H}_{2} \mathrm{O}$ & $32 \% \mathrm{HCl}$ & 5.1 & 48 \\
\hline 6 & $\mathrm{CH}_{3} \mathrm{CN}$ & $32 \% \mathrm{HCl}$ & 5.1 & 61 \\
\hline 7 & $\mathrm{CH}_{3} \mathrm{CN}^{\mathrm{b}}$ & $32 \% \mathrm{HCl}$ & 5.1 & 78 \\
\hline 8 & $\mathrm{CH}_{3} \mathrm{CN}^{\mathrm{b}}$ & $32 \% \mathrm{HCl}$ & 1.1 & 100 \\
\hline 9 & $\mathrm{CH}_{3} \mathrm{CN}^{\mathrm{b}}$ & 1.25 M Ethanolic & 1.1 & 100 \\
\hline
\end{tabular}

Standard conditions: aniline (1.0 equiv., $0.66 \mathrm{M}$ ), isopentyl nitrite (1.1 equiv.), acid (5.1 or 1.1 eq.), $\mathrm{NaBF}_{4}$ (2.0 equiv.), $30 \mathrm{~min}, 0^{\circ} \mathrm{C}$. ${ }^{a}$ minimal amount of DMSO was used to solubilise the $\mathrm{NaBH}_{4}$ prior to addition. ${ }^{b} \mathrm{NaBF}_{4}$ packed in a syringe through which the reaction mixture was passed, 15 min residence time for step 1.

Under solvent-free conditions, the conversion to 1 a was very poor at only $3 \%$ (entry 1). The use of DMF, ethanol or water, either alone or as mixtures, afforded improvements in the yields, however, these were, at best, only moderate at $19-48 \%$ (entries $2-5$ ). When using acetonitrile, the yield improved to $61 \%$ (entry 6). In the latter case, the reagents, apart from sodium tetrafluoroborate, appeared to be solubilised at a concentration of $0.66 \mathrm{M}$ relative to aniline. The yield was further improved to $78 \%$ by initially performing the diazotisation step at $0{ }^{\circ} \mathrm{C}$, followed by passing the reaction mixture through a syringe packed with sodium tetrafluoroborate (2.0 equiv.) three times (entry 7 ). 
In an effort to minimise the amount of acid used, the reaction was then optimised in terms of the stoichiometric excess of the acid. Fortuitously, when decreasing the excess from 5.1 equivalents to 1.1 equivalents, the yield improved to $100 \%$ (entry 8 ). To avoid the use of corrosive aqueous hydrochloric acid, the process was repeated using ethanolic hydrochloric acid $(1.25 \mathrm{M})$ which afforded quantitative isolated yields at 1.1 equivalents of the acid (entry 9). Finally, reduction of the reaction time (step 1) to 15 minutes afforded comparable results.

The final optimised process involved the diazotisation of aniline ( $0.66 \mathrm{M}, 1.0$ equiv.) with iso-pentyl nitrite (1.1 equiv.) and ethanolic hydrochloric acid $\left(1.25 \mathrm{M}, 1.1\right.$ equiv.) in acetonitrile at $0^{\circ} \mathrm{C}$ (15 min reaction time), prior to passage across a syringe packed with sodium tetrafluoroborate (2.0 equiv.), to afford the desired aryl tetrafluoroborate salt (Scheme 2).

In order to convert the process to flow, the general setup depicted in scheme 2 was developed using a Uniqsis FlowSyn SS reactor (Figure 1). The setup involved the use of two HPLC pumps connected via a T-piece adaptor to a $2 \mathrm{~mL}$ PTFE coil reactor (both at $0{ }^{\circ} \mathrm{C}$ ). The coil reactor was, in turn, connected in series to an Omnifit ${ }^{\circledR}$ column housing sodium tetrafluoroborate (at ambient temperature), followed by a back-pressure regulator fitted at the output flow stream.
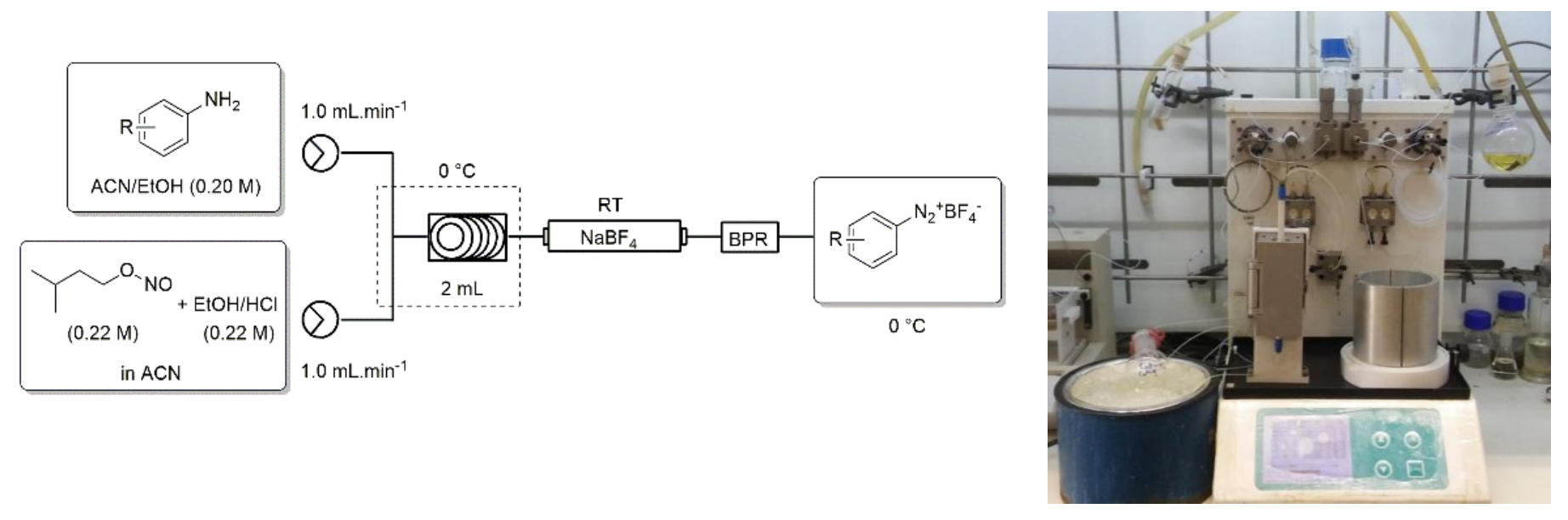

Scheme 2. Schematic representation of our flow set-up for the Figure 1. Uniqsis FlowSyn SS reactor conversion of anilines to aryldiazonium tetrafluoroborates. set-up for the synthesis of aryldiazonium tetrafluoroborates. 
Table 2. Reaction scope

\begin{tabular}{|c|c|c|c|c|c|c|}
\hline & & R- & $\begin{array}{c}\begin{array}{c}\text { 1. isopentyl nitrite, } \\
\text { ethanolic } \mathrm{HCl}\end{array} \\
\underset{2 . \mathrm{NaBF}_{4}}{\longrightarrow}\end{array}$ & 2a-I & & \\
\hline \multirow{2}{*}{ Entry } & \multirow{2}{*}{ Aniline } & \multirow{2}{*}{ Product } & \multirow{2}{*}{ Solvent system } & \multirow{2}{*}{$\begin{array}{c}\text { Flow Rate (ml } \\
\left.\min ^{-1}\right)\end{array}$} & \multicolumn{2}{|c|}{ Yield (\%) } \\
\hline & & & & & Batch & Flow \\
\hline 1 & $1 a$ & & $\begin{array}{c}93 \% \\
\mathrm{CH}_{3} \mathrm{CN} / \mathrm{EtOH}\end{array}$ & 2.0 & 100 & 100 \\
\hline 2 & $1 b$ & & $\begin{array}{c}60 \% \\
\mathrm{CH}_{3} \mathrm{CN} / \mathrm{EtOH}\end{array}$ & 2.0 & 40 & 85 \\
\hline 3 & $1 c$ & & $\begin{array}{c}80 \% \\
\mathrm{CH}_{3} \mathrm{CN} / \mathrm{EtOH}\end{array}$ & 2.0 & 31 & 64 \\
\hline 4 & $1 d$ & & $\begin{array}{c}60 \% \\
\mathrm{CH}_{3} \mathrm{CN} / \mathrm{EtOH}\end{array}$ & 2.0 & 77 & 100 \\
\hline 5 & $1 e$ & & $\begin{array}{c}50 \% \\
\mathrm{CH}_{3} \mathrm{CN} / \mathrm{EtOH}\end{array}$ & 1.5 & 21 & 100 \\
\hline 6 & $1 f$ & & $\begin{array}{c}76 \% \\
\mathrm{CH}_{3} \mathrm{CN} / \mathrm{EtOH}\end{array}$ & 2.0 & 80 & 98 \\
\hline 7 & $1 \mathrm{~g}$ & & $\begin{array}{c}76 \% \\
\mathrm{CH}_{3} \mathrm{CN} / \mathrm{EtOH}\end{array}$ & 2.0 & 90 & 99 \\
\hline 8 & $1 \mathrm{~h}$ & & $\begin{array}{c}76 \% \\
\mathrm{CH}_{3} \mathrm{CN} / \mathrm{EtOH}\end{array}$ & 2.0 & 100 & 100 \\
\hline 9 & $1 \mathrm{i}$ & & $\begin{array}{c}76 \% \\
\mathrm{CH}_{3} \mathrm{CN} / \mathrm{EtOH}\end{array}$ & 2.0 & 99 & 100 \\
\hline 10 & $1 \mathrm{j}$ & & $\begin{array}{c}93 \% \\
\mathrm{CH}_{3} \mathrm{CN} / \mathrm{EtOH}\end{array}$ & 2.0 & 83 & 100 \\
\hline 11 & $1 \mathrm{k}$ & & $\begin{array}{c}60 \% \\
\mathrm{CH}_{3} \mathrm{CN} / \mathrm{EtOH}\end{array}$ & 2.0 & 36 & - \\
\hline 12 & 11 & & $\begin{array}{c}60 \% \\
\mathrm{CH}_{3} \mathrm{CN} / \mathrm{EtOH}\end{array}$ & 1.75 & 75 & 99 \\
\hline
\end{tabular}

Standard conditions: Batch: aniline (1.0 equiv., $0.66 \mathrm{M})$, isopentyl nitrite (1.1 equiv.), ethanolic hydrochloric acid (1.1 eq.), $\mathrm{NaBF}_{4}\left(2.0\right.$ equiv.), $15 \mathrm{~min}, 0^{\circ} \mathrm{C}$ (step 1), rt (step 2). Flow: (Scheme 2, Figure 1): aryl amine (1.0 equiv., $0.20 \mathrm{M}$ ), isopentyl nitrite (1.1 equiv.), ethanolic hydrochloric acid (1.1 equiv.), $\mathrm{NaBF}_{4}$ (2.0 equiv.). 
The process was initially envisaged with the diazotisation occurring in a cooled mixing chip, prior to passage through the Omnifit ${ }^{\circledR}$ column housing the sodium tetrafluoroborate. Unfortunately, although not apparent in batch-mode, when utilising a mixing chip there was a gradual build-up of the precipitated diazonium hydrochloride salt in the chip, which ultimately led to reactor fouling. In an attempt to overcome this issue, the reaction concentration was reduced from $0.66 \mathrm{M}$ to $0.2 \mathrm{M}$ and an ethanol/acetonitrile solvent mix was adopted. The problem persisted, however, and not wanting to dilute the reaction mixture further, we exchanged the mixing chip for a T-piece mixer connected in series to a $2 \mathrm{~mL}$ PTFE coil reactor (id $1 \mathrm{~mm}$ ), which we felt would be less likely to suffer from blockages. Reactor fouling was avoided utilising this set-up, and there was no visual evidence of the build-up of solids occurring inside the PTFE tubing. Thereafter, using aniline as a model system, the process was optimised in terms of residence time, ultimately affording pure benzenediazonium tetrafluoroborate $1 \mathrm{a}$ in quantitative yield with a residence time of $2 \mathrm{~min} 39 \mathrm{sec}$ at a flow rate of $2 \mathrm{~mL} \mathrm{~min}^{-1}$. Off-line processing and purification conveniently only required the removal of solvent and trituration of the resulting residue in tetrahydrofuran to afford the pure tetrafluoroborate salt. The scope of the reaction was then tested through the syntheses of a range of aryl diazonium tetrafluoroborate salts (Table 2) from their respective aryl amines, requiring only minor adjustments to the solvent system or flow rates used. The set-up afforded most of the desired tetrafluoroborate salts in isolated yields of $98-100 \%$ except for 4-methylbenzenediazonium tetrafluoroborate $\mathbf{1 b}(85 \%)$ and 2-hydroxybenzenediazonium tetrafluoroborate $\mathbf{1 c}$ (64\%) (entries 2 and 3). In the case of 4-sulfamoylbenzenediazonium tetrafluoroborate $\mathbf{1 k}$, the sulfanilamide starting reagent could not be sufficiently solubilized for use in the flow reactor (entry 11). In all cases apart from entry 11, the flow yields were equal to or better than the corresponding batch yields.

\section{Conclusions}

We have successfully developed a concise, rapid and high-yielding flow method for the synthesis of aryldiazonium tetrafluoroborates. The flow approach notably affords similar or improved yields when compared to existing batch approaches, and does not require the handling or isolation of the unstable diazonium chloride salt precursors which are generated and consumed in situ. Importantly, the approach as described does not suffer from the build-up of precipitates, and there was no observed formation of unwanted diphenyl diazene byproducts that have been noted previously. ${ }^{17}$ Furthermore, minimal off-line processing and purification are required, with pure material isolated by simple solvent removal and trituration in tetrahydrofuran. The used of a packed-bed reactor to house the sodium tetrafluoroborate, which is used stoichiometrically, suggests that this approach is less amenable to scale-up than previously reported approaches. ${ }^{7,17-18}$ We believe, however, that it offers a mild and easily implemented alternative that is of value in circumstances in which the preparation and isolation of gram quantities of pure aryldiazonium tetrafluoroborates are required. Investigations into telescoping the described setup into reactions wherein the obtained tetrafluoroborates are further functionalised are ongoing in our laboratory.

\section{Experimental Section}

General. Solvents and reagents were purchased from Sigma-Aldrich and used without further purification. ${ }^{1} \mathrm{H}$, ${ }^{13} \mathrm{C}$ and ${ }^{19} \mathrm{~F}$ NMR spectra were recorded on a Bruker AVANCE-III $300 \mathrm{MHz}$ spectrometer or a Bruker AVANCE-III 
$400 \mathrm{MHz}$ spectrometer with the residual solvent peak as an internal reference (DMSO- $d_{6}=2.49$ and $39.5 \mathrm{ppm}$ for ${ }^{1} \mathrm{H}$ and ${ }^{13} \mathrm{C} N M R$, respectively). Chemical shifts, $\delta$, are reported in parts per million (ppm), and splitting patterns are given as singlet $(\mathrm{s})$, doublet $(\mathrm{d})$, triplet $(\mathrm{t})$, quartet $(q)$, or multiplet $(\mathrm{m})$. Coupling constants, $J$, are expressed in hertz $(\mathrm{Hz})$. Infrared spectra were run on a Bruker ALPHA platinum ATR spectrometer. The absorptions are reported on the wavenumber $\left(\mathrm{cm}^{-1}\right)$ scale, in the range of $400-4000 \mathrm{~cm}^{-1}$. Yields refer to isolated pure products unless stated otherwise. Flow reactions were performed on a Uniqsis FlowSyn Stainless Steel reactor.

Typical batch synthesis of aryl diazonium tetrafluoroborate salts (table 1 entry 10). A solution of aryl amine ( $2 \mathrm{mmol}, 1.0$ equiv.) in acetonitrile $(5 \mathrm{ml})$ was cooled to $0{ }^{\circ} \mathrm{C}$. Ethanolic hydrochloric acid $(2.2 \mathrm{mmol}, 1.1$ equiv.) was added to the solution in a drop-wise fashion followed by drop-wise addition of isopentyl nitrite $(2.2 \mathrm{mmol}$, 1.1 equiv.). The reaction mixture was stirred for $15 \mathrm{~min}$ after which time it was passed through a syringe packed with sodium tetrafluoroborate $(4 \mathrm{mmol}, 2.0$ equiv.) at ambient temperature $(3 \mathrm{x})$. After the third pass, the output of the syringe was collected, cooled to $0{ }^{\circ} \mathrm{C}$, and followed by concentration to dryness. The residue obtained was then suspended in tetrahydrofuran facilitating the precipitation of the pure aryldiazonium tetrafluoroborate salts which were then collected by vacuum filtration and washed with tetrahydrofuran (Table 1 entries).

Typical flow synthesis of aryl diazonium tetrafluoroborate salts (Table 1, entry 1). A solution of aryl amine [11.0 ml, 0.2 $\mathrm{M}$ in $\mathrm{CH}_{3} \mathrm{CN} / \mathrm{EtOH}$ (see ratios in table 2)], and a solution of isopentyl nitrite/ethanolic hydrochloric acid $\left(1.6 \mathrm{~mL} / 9.5 \mathrm{ml}, 0.22 \mathrm{M}\right.$ in $\mathrm{CH}_{3} \mathrm{CN}$ ), were combined at a T-piece mixer (see table 2 for flow rates and scheme 2 for reactor set-up), cooled to $0^{\circ} \mathrm{C}$ and reacted in a $2 \mathrm{~mL}$ HT PTFE coil also cooled to $0^{\circ} \mathrm{C}$. The combined stream was then passed through a glass Omnifit ${ }^{\circledR}$ column packed with sodium tetrafluoroborate (1.25 g, $11.4 \mathrm{mmol}, 2.0$ equiv.) at room temperature, followed by passage through a back-pressure regulator. The output stream was collected in a flask cooled to $0{ }^{\circ} \mathrm{C}$, concentrated to dryness, and re-suspended in tetrahydrofuran, facilitating the precipitation of the pure aryldiazonium tetrafluoroborate salts, which were then collected by vacuum filtration and washed with tetrahydrofuran.

Benzenediazonium tetrafluoroborate (1a). The titled compound was prepared following either protocol A or $B$ affording a light pink solid (batch: $3.3 \mathrm{mmol}$ scale, $0.63 \mathrm{~g}, 100 \%$; flow: $2.2 \mathrm{mmol}$ scale, $0.42 \mathrm{~g}, 100 \%) .{ }^{1} \mathrm{H}-\mathrm{NMR}$ (300 MHz DMSO- $d_{6}$ ); $\delta=8.65$ (d, 2H, J $8.07 \mathrm{~Hz}$ ), 8.25 (dd, $1 \mathrm{H}, J 7.28 \& 7.28 \mathrm{~Hz}$ ), 7.97 (dd, $2 \mathrm{H}, J 7.85 \& 7.85 \mathrm{~Hz}$ ). ${ }^{13} \mathrm{C}-\mathrm{NMR}\left(75 \mathrm{MHz}\right.$ DMSO- $\left.d_{6}\right) ; \delta=140.92,132.69,131.29,116.02 .{ }^{19} \mathrm{~F} \mathrm{NMR}\left(282 \mathrm{MHz}, \mathrm{DMSO}-d_{6}\right) ; \delta=-148.30 . \mathrm{IR}$ $\mathrm{cm}^{-1}$ (neat) 3105, 2292, 1016, 754, 662. Data match those previously reported. ${ }^{22}$

4-Methylbenzenediazonium tetrafluoroborate (1b). The titled compound was prepared following either protocol A or B affording a light brown solid (batch: $2.0 \mathrm{mmol}$ scale, $0.16 \mathrm{~g}, 40 \%$; flow: $2.0 \mathrm{mmol}$ scale, $0.34 \mathrm{~g}$, 85\%). ${ }^{1} \mathrm{H}-\mathrm{NMR}\left(300 \mathrm{MHz}\right.$ DMSO- $\left.d_{6}\right) ; \delta=8.53\left(\mathrm{~d}, 2 \mathrm{H}, \mathrm{J} 8.46 \mathrm{~Hz}\right.$ ), 7.79 (d, 2H J 8.37), 2.56 (s, 3H). ${ }^{13} \mathrm{C}-\mathrm{NMR}(75$ $\mathrm{MHz}$ DMSO- $\left.d_{6}\right) ; \delta=154.02,132.67,131.81,111.94,22.39 .{ }^{19} \mathrm{~F} \mathrm{NMR}\left(282 \mathrm{MHz}\right.$, DMSO- $\left.d_{6}\right) ; \delta=-148.26 . \mathrm{IR}^{-1}$ (neat) $3111,2286,1581,1011,817,723$. Data match those previously reported. ${ }^{22}$

2-Hydroxybenzenediazonium tetrafluoroborate (1c). The titled compound was prepared following either protocol A or B affording an off-white solid (batch: $1.95 \mathrm{mmol}$ scale, $0.12 \mathrm{~g}, 31 \%$; flow: $1.88 \mathrm{mmol}$ scale, 0.26 g, 64\%). ${ }^{1} \mathrm{H}-\mathrm{NMR}(300 \mathrm{MHz}$ DMSO-d 6 ); $\delta=7.60(\mathrm{~d}, 1 \mathrm{H}, J 8.04 \mathrm{~Hz}$ ), $7.42(\mathrm{dd}, 1 \mathrm{H}, J 7.86 \& 7.86 \mathrm{~Hz}), 6.84(\mathrm{~s}, 1 \mathrm{H})$, $6.59(\mathrm{~d}, 1 \mathrm{H}, J 9.24 \mathrm{~Hz}), 6.37$ (dd, $1 \mathrm{H}, J 7.48$ \& 7.48). ${ }^{13} \mathrm{C}-\mathrm{NMR}(75 \mathrm{MHz}$ DMSO-d 6 ); $\delta=173.43,139.91,127.21$, 121.68, 116.02, 91.35. $\left.{ }^{19} \mathrm{~F} \mathrm{NMR} \mathrm{(282} \mathrm{MHz,} \mathrm{DMSO-} d_{6}\right) ; \delta=-148.57 . \mathrm{IR} \mathrm{cm}^{-1}$ (neat) 2280, 1306, 1010, $750,608$.

3-Hydroxybenzenediazonium tetrafluoroborate (1d). The titled compound was prepared following either protocol A or B affording a brown solid (batch: $1.95 \mathrm{mmol}$ scale, $0.32 \mathrm{~g}, 77 \%$; flow: $1.90 \mathrm{mmol}$ scale, $0.40 \mathrm{~g}$, 
100\%). ${ }^{1} \mathrm{H}-\mathrm{NMR}\left(300 \mathrm{MHz}\right.$ DMSO- $\left.d_{6}\right) ; \delta=11.41(\mathrm{~s}, 1 \mathrm{H}), 8.10(\mathrm{~d}, 1 \mathrm{H}, J 7.53), 7.94(\mathrm{~s}, 1 \mathrm{H}), 7.74(\mathrm{dd}, 1 \mathrm{H}, J 7.25 \&$ $7.25 \mathrm{~Hz}$ ), 7.60 (d, $1 \mathrm{H}, J$ 6.12). ${ }^{19} \mathrm{~F} \mathrm{NMR}\left(282 \mathrm{MHz}, \mathrm{DMSO}-d_{6}\right) ; \delta=-148.45 . \mathrm{IR} \mathrm{cm}^{-1}$ (neat) $3199,1411,1306,1011$, 725.

4-Hydroxybenzenediazonium tetrafluoroborate (1e). The titled compound was prepared following either protocol A or B affording a white solid (batch: $1.90 \mathrm{mmol}$ scale, $0.09 \mathrm{~g}, 21 \%$; flow: $1.90 \mathrm{mmol}$ scale, $0.40 \mathrm{~g}$, 100\%). ${ }^{1} \mathrm{H}-\mathrm{NMR}\left(300 \mathrm{MHz}\right.$ DMSO-d $\left.d_{6}\right) ; \delta=8.29$ (d, $\left.2 \mathrm{H}, J 9.21 \mathrm{~Hz}\right), 6.96(\mathrm{~d}, 2 \mathrm{H}, J 8.85 \mathrm{~Hz}) .{ }^{19} \mathrm{~F} \mathrm{NMR}(282 \mathrm{MHz}$, DMSO- $d_{6}$ ); $\delta=-148.49$. IR cm $\mathrm{cm}^{-1}$ (neat) 2113, 2082, 1827, 1305, 1012, 595.

4-Chlorobenzenediazonium tetrafluoroborate (1f). The titled compound was prepared following either protocol A or B affording white solid (batch: $1.88 \mathrm{mmol}$ scale, $0.33 \mathrm{~g}, 80 \%$; flow: $1.74 \mathrm{mmol}$ scale, $0.39 \mathrm{~g}, 98 \%$ ). ${ }^{1} \mathrm{H}-\mathrm{NMR}\left(300 \mathrm{MHz}\right.$ DMSO- $\left.d_{6}\right) ; \delta=8.68(\mathrm{~d}, 2 \mathrm{H}, J 8.91 \mathrm{~Hz}), 8.10(\mathrm{~d}, 2 \mathrm{H}, J 8.91 \mathrm{~Hz}) .{ }^{13} \mathrm{C}-\mathrm{NMR}\left(75 \mathrm{MHz} \mathrm{DMSO}-d_{6}\right)$; $\delta=146.57,134.42,131.63,114.72 .{ }^{19} \mathrm{~F} \mathrm{NMR}\left(282 \mathrm{MHz}, \mathrm{DMSO}-d_{6}\right) ; \delta=-148.26 . \mathrm{IR} \mathrm{cm}^{-1}$ (neat) 3108, 2289, $1313,1290,1024,833,771$.

4-Bromobenzenediazonium tetrafluoroborate (1). The titled compound was prepared following either protocol A or B affording a white solid (batch: $1.55 \mathrm{mmol}$ scale, $0.37 \mathrm{~g}, 90 \%$; flow: $1.52 \mathrm{mmol}$ scale, $0.40 \mathrm{~g}$, 99\%). ${ }^{1} \mathrm{H}-\mathrm{NMR}\left(300 \mathrm{MHz}\right.$ DMSO- $\left.d_{6}\right) ; \delta=8.56(\mathrm{~d}, 2 \mathrm{H}, J 8.88 \mathrm{~Hz}) ; 8.24(\mathrm{~d}, 2 \mathrm{H}, J 8.88 \mathrm{~Hz}) .{ }^{13} \mathrm{C}-\mathrm{NMR}(75 \mathrm{MHz}$ DMSO- $\left.d_{6}\right) ; \delta=136.58,134.56,133.98,115.14 .{ }^{19} \mathrm{~F} \mathrm{NMR}\left(282 \mathrm{MHz}\right.$, DMSO- $\left.d_{6}\right) ; \delta=-148.23$. IR cm ${ }^{-1}$ (neat) 3097 , $2282,1291,1029,827,759$. Data match those previously reported. ${ }^{22}$

2-Fluorobenzenediazonium tetrafluoroborate (1h). The titled compound was prepared following either protocol A or B affording a light-yellow solid (batch: $2.1 \mathrm{mmol}$ scale, $0.44 \mathrm{~g}, 100 \%$; flow: $1.9 \mathrm{mmol}$ scale, $0.40 \mathrm{~g}$, 100\%). ${ }^{1} \mathrm{H}-\mathrm{NMR}\left(300 \mathrm{MHz}\right.$ DMSO- $\left.d_{6}\right) ; \delta=8.73(\mathrm{dd}, 1 \mathrm{H}, J 6.63 \& 6.63 \mathrm{~Hz}), 8.37(\mathrm{dd}, 1 \mathrm{H}, J 7.10 \& 13.52 \mathrm{~Hz}), 7.99$ (dd, $1 \mathrm{H}, J 9.18 \& 9.18 \mathrm{~Hz}), 7.81(\mathrm{dd}, 1 \mathrm{H}, J 7.95 \& 7.95 \mathrm{~Hz}) .{ }^{13} \mathrm{C}-\mathrm{NMR}\left(75 \mathrm{MHz} \mathrm{DMSO}-d_{6}\right) ; \delta=162.17,158.55$, $144.78,144.66,133.46,133.41,127.47,118.81,118.60,105.65,105.48 .{ }^{19} \mathrm{~F} \mathrm{NMR}\left(282 \mathrm{MHz}, \mathrm{DMSO}-d_{6}\right) ; \delta=-$ 102.55, 148.37. IR cm ${ }^{-1}$ (neat) 3106, 2292, 1287, 1250, 1029, 830, 769.

3-Fluorobenzenediazonium tetrafluoroborate (1i). The titled compound was prepared following either protocol A or B affording a white coloured solid (batch: $2.1 \mathrm{mmol}$ scale, $0.43 \mathrm{~g}, 99 \%$; flow: $1.9 \mathrm{mmol}$ scale, 0.40 g, 100\%). ${ }^{1} \mathrm{H}-\mathrm{NMR}(300 \mathrm{MHz}$ DMSO-d $\left.)\right) ; \delta=8.66(\mathrm{~d}, 1 \mathrm{H}, J 7.59 \mathrm{~Hz}), 8.58(\mathrm{~d}, 1 \mathrm{H}, J 8.28 \mathrm{~Hz}), 8.21(\mathrm{dd}, 1 \mathrm{H}, J 8.45$ \& $8.45 \mathrm{~Hz}), 8.00-8.08(\mathrm{~m}, 1 \mathrm{H}) .{ }^{13} \mathrm{C}-\mathrm{NMR}\left(75 \mathrm{MHz}\right.$ DMSO- $\left.d_{6}\right) ; \delta=161.86,159.35,133.65,133.56,129.89$, $129.86,129.30,129.09,119.69,119.39,117.41,117.29 .{ }^{19} \mathrm{~F} \mathrm{NMR}\left(282 \mathrm{MHz}\right.$, DMSO- $\left.d_{6}\right) ; \delta=-105.75,-148.24$. IR $\mathrm{cm}^{-1}$ (neat) 3101, 2300, 1235, 1028, 874, 789, 651.

4-Fluorobenzenediazonium tetrafluoroborate (1j). The titled compound was prepared following either protocol A or B affording a light-yellow solid (batch: $2.05 \mathrm{mmol}$ scale, $0.37 \mathrm{~g}$, 83\%; flow: $1.9 \mathrm{mmol}$ scale, $0.40 \mathrm{~g}$, 100\%). ${ }^{1} \mathrm{H}-\mathrm{NMR}\left(300 \mathrm{MHz} \mathrm{DMSO}-d_{6}\right) ; \delta=8.77-8.82(\mathrm{~m}, 2 \mathrm{H}), 7.84-7.90(\mathrm{~m}, 2 \mathrm{H}) .{ }^{13} \mathrm{C}-\mathrm{NMR}$ (75 MHz DMSO$\left.d_{6}\right) ; \delta=169.80,167.14,137.08,136.96,119.55,119.30,111.87,111.84 .{ }^{19} \mathrm{~F} \mathrm{NMR}\left(282 \mathrm{MHz}, \mathrm{DMSO}-d_{6}\right) ; \delta=-$ $87.21,-148.17$. IR cm$^{-1}$ (neat) $3114,2291,1252,1016,843,682$. Data match those previously reported. ${ }^{22}$

4-Sulfamoylbenzenediazonium tetrafluoroborate (1k). The titled compound was prepared following either protocol A affording a pale-yellow solid (batch: $1.65 \mathrm{mmol}$ scale, $0.15 \mathrm{~g}, 36 \%) .{ }^{1} \mathrm{H}-\mathrm{NMR}\left(300 \mathrm{MHz} \mathrm{DMSO}-d_{6}\right) ; \delta$ $=8.85\left(\mathrm{~d}, 2 \mathrm{H}, J\right.$ 8.73), $8.32(\mathrm{~d}, 2 \mathrm{H}, J 8.76), 8.04(\mathrm{~s}, 2 \mathrm{H}) .{ }^{13} \mathrm{C}-\mathrm{NMR}\left(75 \mathrm{MHz}\right.$ DMSO- $\left.d_{6}\right) ; \delta=153.37,134.05$, 128.06, 119.46. ${ }^{19} \mathrm{~F} \mathrm{NMR}\left(282 \mathrm{MHz}\right.$, DMSO- $\left.d_{6}\right) ; \delta=-148.25 . \mathrm{IR} \mathrm{cm}^{-1}$ (neat) 2079, 1663, 1306, $1011,618$.

2-Carboxybenzenediazonium tetrafluoroborate (1). The titled compound was prepared following either protocol A or B affording a white solid (batch: $1.73 \mathrm{mmol}$ scale, $0.31 \mathrm{~g}, 75 \%$; flow: $1.72 \mathrm{mmol}$ scale, $0.40 \mathrm{~g}$, 99\%). ${ }^{1} \mathrm{H}-\mathrm{NMR}\left(300 \mathrm{MHz}\right.$ DMSO- $\left.d_{6}\right) ; \delta=12.21(\mathrm{~s}, \mathrm{br}, 1 \mathrm{H}), 7.71(\mathrm{dd}, 1 \mathrm{H}, J 8.04 \& 1.46 \mathrm{~Hz}), 7.56(\mathrm{dd}, 1 \mathrm{H}, J 8.58$ \& $8.58 \mathrm{~Hz}$ ), $7.12(\mathrm{~d}, 1 \mathrm{H}, J 7.72 \mathrm{~Hz}), 7.10\left(\mathrm{~d}, 1 \mathrm{H}, J\right.$ 7.52). $\left.{ }^{13} \mathrm{C}-\mathrm{NMR}(75 \mathrm{MHz} \text { DMSO-d })_{6}\right) ; \delta=172.33,157.50,135.29$, 
130.36, 129.77, 120.62, 116.96. $\left.{ }^{19} \mathrm{~F} \mathrm{NMR} \mathrm{(282} \mathrm{MHz,} \mathrm{DMSO-} d_{6}\right) ; \delta=-148.33 . \mathrm{IR} \mathrm{cm}^{-1}$ (neat) 3099, 2281, 1728, $1047,725,635$.

\section{Acknowledgements}

This work was supported by the National Research Foundation of South Africa (grant numbers 87893 and 106959), the University of Pretoria (University, Science Faculty Research Councils and Research and Development Program), South Africa and the Department of Science and Technology and Pelchem Pty Ltd. Opinions expressed in this chapter, and the conclusions arrived at, are those of the authors, and are not necessarily attributed to the NRF. The author would like to acknowledge Mamoalosi Selepe for NMR spectroscopy services.

\section{Supplementary Material}

Supplementary data associated with this paper can be found in the online version.

\section{References}

1. Mohamed, A.A.; Salmi, Z.; Dahoumane, S.A.; Mekki, A.; Carbonnier, B.; Chehimi, M.M. Adv. Colloid Interface Sci. 2015, 225, 16.

https://doi.org/10.1016/i.cis.2015.07.011

2. Mo, F.; Dong, G.; Zhang, Y.; Wang, J. Org. Biomol. Chem., 2013, 11, 1582.

https://doi.org/10.1039/c3ob27366k

3. Ram, R.N.; Singh, V. J. Chem. Res., 2006, 800.

https://doi.org/10.3184/030823406780199848

4. Maas, G.; Tanaka, M.; Sakakura, T. Benzenediazonium Tetrafluoroborate, Section in Encyclopaedia of Reagents for Organic Synthesis 2nd Ed., book 1., Paquette, L.A.; D. Crich, P.L. Fuchs and G.A.

Molander(eds.), Wiley, 2009, 436 - 441.

5. Wootton, R.C.R.; Fortt, R.; de Mello, J. Lab Chip, 2002, 2, 5.

https://doi.org/10.1039/B111286D

6. Fortt, R.; Wootton, R.C.R.; de Mello, J. Org. Process Res. Dev., 2003, 7, 762.

https://doi.org/10.1021/op025586j

7. Li, B.; Widlicka, D.; Boucher, S.; Hayward, C.; Lucas, J.; Murray, J.C.; O’Neil, B.T.; Pfisterer, D.; Samp, L.; Van Alsten, J.; Xiang, Y.; Young, J. Org. Process Res. Dev., 2012, 16, 2031.

https://doi.org/10.1021/op300209p

8. Oger, N.; Le Grognec, E.; Felpin, F.-X.; J. Org. Chem., 2014, 79, 8255. https://doi.org/10.1021/j0501468z

9. Ahmed-Omer, B.; Barrow D.A.; Wirth, T. Tetrahedron Lett., 2009, 50, 3352.

https://doi.org/10.1016/j.tetlet.2009.02.133

10. Chen M.; Buchwald, S.L. Angew. Chem. Int. Ed., 2013, 52, 4247. 
https://doi.org/10.1002/anie.201306094

11. Yu, Z.; Xie, X.; Dong, H.; Liu, J.; Su, W.; Org. Process Res. Dev., 2016, 20, 774.

https://doi.org/10.1021/acs.oprd.6b00023

12. Malet-Sanz, L.; Madrzak, J.; Holvey, R.S. ; Underwood, T. Tetrahedron Lett., 2009, 50, 7263.

https://doi.org/10.1016/j.tetlet.2009.10.007

13. Malet-Sanz, L.; Madrzak, J.; Ley, S.V.; Baxendale, I.R. Org. Biomol. Chem., 2010, 8, 5324. https://doi.org/10.1039/c0ob00450b

14. Jacq, J.; Pasau, P.; Chem. Eur. J., 2014, 20, 12223.

ttps://doi.org/10.1002/ejic.201490002

15. D’Attoma, J.; Camara, T.; Brun, P.L.; Robin, Y.; Bostyn, S.; Buron, F.; Routier, S. Org. Process Res. Dev., 2017, 21, 44.

https://doi.org/10.1021/acs.oprd.6b00318

16. Oger, N.; Le Grognec, E.; Felpin, F.-X.; Org. Chem. Front., 2015, 2, 590.

https://doi.org/10.1039/C5Q000037H

17. Yu, Z.-Q.; Lv, Y.-W.; Yu, C.-M.; Su, W.-K. Tetrahedron Lett., 2013, 54, 1261.

https://doi.org/10.1016/i.tetlet.2012.12.084

18. Hu, T.; Baxendale, I.R.; Baumann, M. Molecules, 2016, 21, 918.

https://doi.org/10.3390/molecules21070918

19. Colleville, A.P.; Horan R.A.J.; Tomkinson, N.C.O. Org. Process Res. Dev., 2014, 18, 1128.

https://doi.org/10.1021/op5002353

20. Furniss, B.S.; Hannaford, A.J.; Smith, P.W.; Tatchell, A.R. Formation of diazonium salts and their uses in Vogel's Textbook of Practical Organic Chemistry 5th Ed., Pearson Prentice Hall, 1989, 920 - 953.

21. Hudlicky, M. Replacement of Nitrogen by Fluorine in Chemistry of Organic Fluorine Compounds 2 nd Ed., E. Horwood and J. Mellor (eds.), Ellis Horwood and Prentice Hall, 1992, 160 - 169.

22. Gribanov, P.S.; Topcchiy, M.A.; Golenko, Y.D.; Lichtenstein, Y.I.; Eshtukov, A.V.; Terekhov, V.E.; Asachenko A.F.; Nechaev, M.S. Green Chem., 2016, 18(22), 5984-5988.

https://doi.org/10.1039/C6GC02379G 